\title{
Israel restores Asiatic wild ass
}

\author{
Bill Clark
}

In April 1982 Israeli conservationists released a test herd of Asiatic wild ass Equus hemionus into the central Negev Desert basin of Makhtesh Ramon as the first step in restoring this species into the wild. The five males are being closely monitored to determine how well they adjust to their freedom and if no serious problems are encountered they will be joined by females.

The released animals are Equus hemionus onager, the closest living relative of Equus hemionus hemippus, the subspecies which once inhabited the region, until the present century, but is now considered extinct. They are progeny of stock acquired by Israel's Hai-Bar Society from European zoos in 1968 and kept in the $35 \mathrm{sq} \mathrm{km}$ Hai-Bar Arava Wildlife Reserve $40 \mathrm{~km}$ north of the Red Sea port, Eilat.

During the 14 years at Hai-Bar, the onagers, which occur naturally in Iran, made several biological adjustments to the Israeli environment, particularly its earlier spring and hotter summer. The Israeli onagers now shed winter coats a month earlier than their Iranian counterparts, and the foaling season has also shifted nearly a month earlier. Israeli onager adults mature at a slightly smaller size, and their summer coats tend to be lighter. All these adjustments suggest the Israeli onagers are becoming more like the extinct hemippus race, and confirm that subspecific variations are essentially a reflection of habitat. The Hai-Bar onager herds now number about 50 animals, divided into two harem herds, and two bachelor herds, all living at freedom within the reserve.

Bill Clark, Chief Curator, Hai-Bar Arava Wildlife Reserve, 3 Rehov Diskin, Jerusalem 92473, Israel.

Oryx Vol 17 No 3

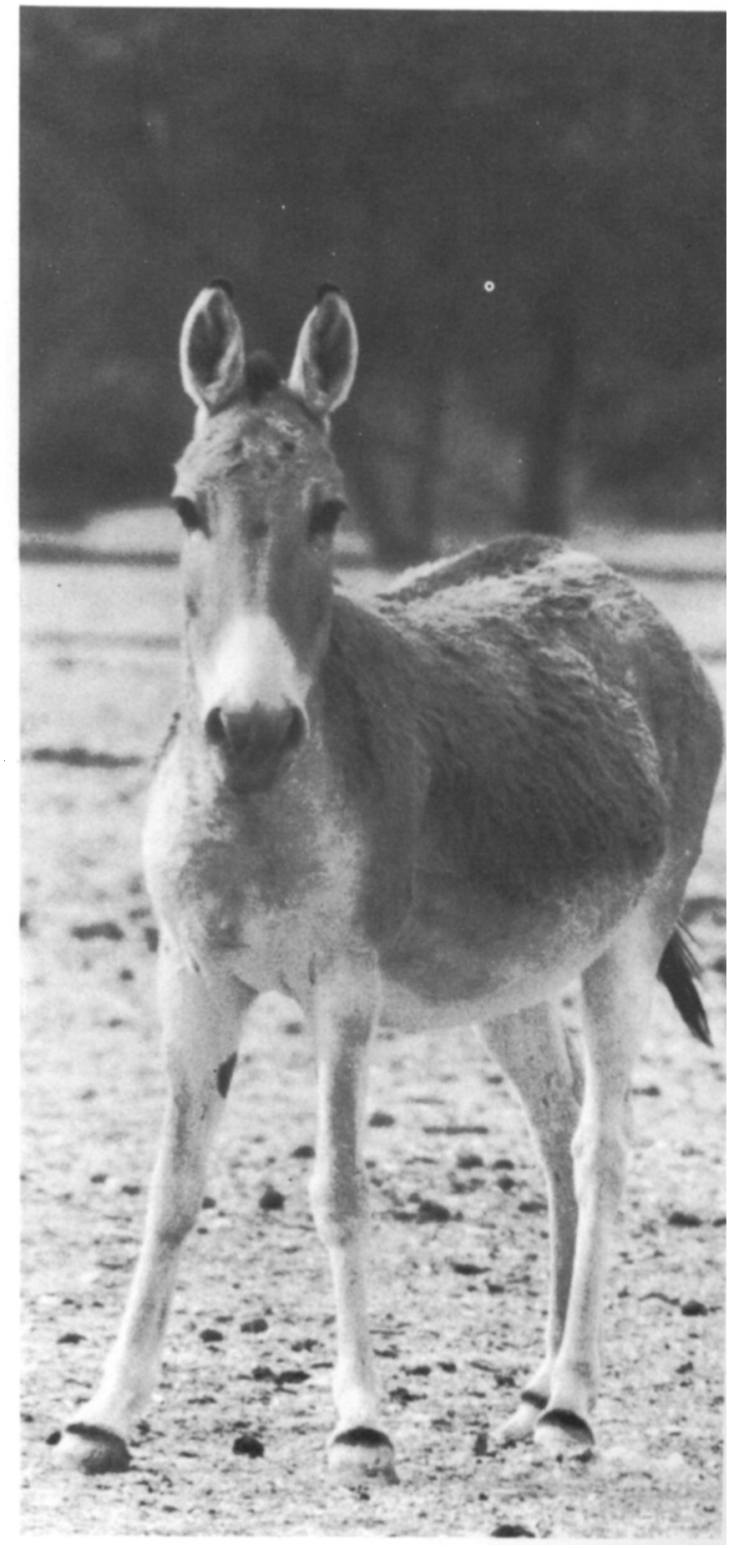

Equus hemionus stallion released into Israel's Negev Desert. (Bill Clark)

113 